\title{
Q.
QNEEN'S
UNIVERSITY
BELFAST
}

\section{Physical activity promotion and the United Nations Sustainable Development Goals: building synergies to maximize impact}

Salvo, D., Garcia, L., Reis, R., Stankov, I., Goel, R., Schipperijn, J., Hallal, P. C., Ding, D., \& Pratt, M. (2021). Physical activity promotion and the United Nations Sustainable Development Goals: building synergies to maximize impact. Journal of Physical Activity and Health, 18(10), 1163-1180. https://doi.org/10.1123/jpah.20210413

Published in:

Journal of Physical Activity and Health

Document Version:

Publisher's PDF, also known as Version of record

Queen's University Belfast - Research Portal:

Link to publication record in Queen's University Belfast Research Portal

Publisher rights

(๖) 2021 Human Kinetics, Inc. This work is made available online in accordance with the publisher's policies. Please refer to any applicable terms of use of the publisher.

\section{General rights}

Copyright for the publications made accessible via the Queen's University Belfast Research Portal is retained by the author(s) and / or other copyright owners and it is a condition of accessing these publications that users recognise and abide by the legal requirements associated with these rights.

Take down policy

The Research Portal is Queen's institutional repository that provides access to Queen's research output. Every effort has been made to ensure that content in the Research Portal does not infringe any person's rights, or applicable UK laws. If you discover content in the Research Portal that you believe breaches copyright or violates any law, please contact openaccess@qub.ac.uk. 


\title{
Physical Activity Promotion and the United Nations Sustainable Development Goals: Building Synergies to Maximize Impact
}

\author{
Deborah Salvo, Leandro Garcia, Rodrigo S. Reis, Ivana Stankov, Rahul Goel, Jasper Schipperijn, \\ Pedro C. Hallal, Ding Ding, and Michael Pratt
}

\begin{abstract}
Background: Many of the known solutions to the physical inactivity pandemic operate across sectors relevant to the United Nations Sustainable Development Goals (SDGs). Methods: The authors examined the contribution of physical activity promotion strategies toward achieving the SDGs through a conceptual linkage exercise, a scoping review, and an agent-based model. Results: Possible benefits of physical activity promotion were identified for 15 of the 17 SDGs, with more robust evidence supporting benefits for SDGs 3 (good health and well-being), 9 (industry, innovation, and infrastructure), 11 (sustainable cities and communities), 13 (climate action), and 16 (peace, justice, and strong institutions). Current evidence supports prioritizing atscale physical activity-promoting transport and urban design strategies and community-based programs. Expected physical activity gains are greater for low-and middle-income countries. In high-income countries with high car dependency, physical activity promotion strategies may help reduce air pollution and traffic-related deaths, but shifts toward more active forms of travel and recreation, and climate change mitigation, may require complementary policies that disincentivize driving. Conclusions: The authors call for a synergistic approach to physical activity promotion and SDG achievement, involving multiple sectors beyond health around their goals and values, using physical activity promotion as a lever for a healthier planet.
\end{abstract}

Keywords: public health, policy, environment, sustainability, systematic review/meta-analysis, systems science

\section{KEY POINTS}

- There is strong synergy between physical activity promotion and the Sustainable Development Goals (SDGs), presenting unique opportunities to simultaneously address multiple population health priorities and for achieving several SDGs.

- Synergies between physical activity promotion and meeting several of the SDGs are conceptually coherent and supported by scientific evidence. The evidence is strongest for physical activity promotion strategies involving transport policies, urban design infrastructure, and community-based programs, with observed benefits for SDGs 3 (good health and wellbeing), 9 (industry, innovation, and infrastructure), 11 (sustainable cities and communities), 13 (climate action), and 16 (peace, justice, and strong institutions).

- Socioeconomic and gender-based inequalities (SDGs 10 and 5) are interrelated with physical activity promotion. Resolving

Salvo and Reis are with the Prevention Research Center, Brown School, Washington University in St. Louis, St. Louis, MO, USA. Garcia is with the Centre for Public Health, Queen's University Belfast, Belfast, United Kingdom. Reis is also with the Postgraduate Program in Urban Management, Pontificia Universidade Católica do Paraná, Brazil. Stankov is with the Urban Health Collaborative, Dornsife School of Public Health, Drexel University, Philadelphia, PA, USA. Goel is with MRC Epidemiology Unit, University of Cambridge, Cambridge, United Kingdom. Schipperijn is with the Department of Sport Science and Clinical Biomechanics, University of Southern Denmark, Odense, Denmark. Hallal is with the Postgraduate Program in Epidemiology, Universidade Federal de Pelotas, Pelotas, Brazil. Ding is with the Prevention Research Collaboration, Sydney School of Public Health, Faculty of Medicine and Health, The University of Sydney, Camperdown, NSW, Australia; and Charles Perkins Centre, The University of Sydney, Camperdown, NSW, Australia. Pratt is with Herbert Wertheim School of Public Health and Human Longevity Science, University of California San Diego, La Jolla, CA, USA. Salvo (dsalvo@wustl.edu) is corresponding author. socioeconomic and gender-based inequalities could help improve population levels of physical activity. Conversely, physical activity promotion strategies have the potential to reduce inequalities.

- We present new evidence supporting at-scale physical activity strategies centered on transport systems that prioritize walking, cycling, and transit and on activity-promoting urban design. These strategies can help improve both physical activity and achievement of SDGs. For physical activity, benefits accrue from increases in both the recreational and transport domains. For SDGs, benefits are achieved through improvements in traffic safety (SDG 3), transportation mode share (SDG 9), air pollution (SDG 11), equitable access to public transport and public open spaces (SDG 10 and SDG 11), and reductions in carbon emissions (SDG 13).

- The effects of these strategies are context specific. Cities in low- and middle-income countries (LMICs) may reap more health-related benefits from scaled-up physical activity promotion strategies than cities in high-income countries (HICs) with high car dependency. Car-dependent cities in HICs are responsible for a large proportion of global carbon emissions. In these settings, physical activity promotion policies may help in reducing traffic-related deaths and improving air quality, but to attain meaningful improvements in physical activity levels and climate change, policies may also need to include strategies that reduce car dependence.

- The most effective strategies for increasing physical activity and achieving SDGs are multicomponent and multisectoral. A systems approach is strongly recommended to minimize the risk of unintended consequences and maximize the positive impact of these strategies on physical activity and SDGs.

- Important evidence gaps remain. There may be benefits of physical activity promotion strategies on additional SDGs 
beyond those we have identified; however, the evidence is currently weak or limited. Determining to what extent physical activity promotion strategies can have additional benefits for SDG achievement in different contexts will be key for supporting broader scale-up of physical activity promotion strategies around the globe.

The health of humans and our planet hangs in the balance. The United Nations (UN) SDGs lay out objectives for saving the planet and enhancing quality of life by 2030 , including a goal for ensuring health and well-being for all (SDG 3)., ${ }^{1,2}$ The World Health Organization (WHO) has recognized the link between public health efforts and multiple $\mathrm{SDGs}^{3}$ as the UN sustainable development agenda addresses the multilevel drivers of public health across sectors. Physical inactivity remains a major, unresolved public health challenge, which contributes to an estimated 5 million deaths per year and a large proportion of noncommunicable diseases, costing societies billions of dollars. ${ }^{4-6}$ Recent findings have also unveiled physical activity's protective effects on infectious disease outcomes (including COVID-19). ${ }^{7,8}$ Effective strategies to promote physical activity ${ }^{9}$ can not only reduce disease burden and health care cost but could also offer untapped opportunities for achieving multiple SDGs. However, such synergy has not been explored systematically within a global context.

Because most of the known solutions for addressing the physical inactivity pandemic operate across multiple sectors, large-scale implementation of physical activity promotion strategies could contribute toward the achievement of some of the broader societal, economic, humanitarian, and planetary global priorities of our time. Physical activity promotion may provide much-needed "small victories" for the sustainable development agenda. Unveiling the benefits that physical activity promotion could have for SDG achievement may represent a powerful strategy for achieving the promise of "health in all policies" worldwide. ${ }^{10-12}$

In this article, we examine the potential benefits of large-scale physical activity promotion strategies on SDGs. We do this by: describing the unresolved global pandemic of physical inactivity; identifying plausible linkages between physical activity promotion and SDG achievement and summarizing the existing evidence and gaps; exploring, through an agent-based simulation model, the possible impact of at-scale physical activity promotion strategies on SDG-related outcomes across high-, middle-, and low-income country city types; and synthesizing our results through a set of sector-specific recommendations to guide future policy, research, and community action for physical activity promotion and SDG achievement.

\section{Revisiting the Ongoing Challenge of Global Physical Inactivity}

Since 2012, physical inactivity has been described as a pandemic, responsible for major health and economic burdens. ${ }^{4,6,13,14}$ Multiple solutions to address the pandemic have been summarized by a large body of evidence ${ }^{9,14-17}$ and include physical activity promotion strategies, which are effective at scale and across different sectors, settings, and populations. ${ }^{9,18}$ Resulting calls to action have urged public health researchers, practitioners, governments, and societies at large to take bold actions for reverting the global pandemic of inactivity. ${ }^{4,9,19-21}$ Several policy guiding documents have also been recently published, including the WHO's Global Action Plan on Physical Activity (GAPPA) in 2018, ${ }^{22}$ updates to the US Community Guide, ${ }^{17},{ }^{23-28}$ and new physical activity guidelines by the WHO and individual countries. ${ }^{29-33}$

Despite progress, there remains limited comprehensive policy action commensurate with the size of the problem of the physical inactivity pandemic. ${ }^{4,9,13-15,21}$ This is particularly true in many LMICs, ${ }^{14,34}$ possibly due to the lack of immediately visible negative consequences of physical inactivity, limited resources for health, and other competing priorities (eg, poverty, infectious diseases, malnutrition, etc). ${ }^{35-37}$ In these settings, a large share of physical activity is driven by necessity (ie, occurs within the domains of work and transport and mostly among low-income populations). ${ }^{38,39}$ Cultural norms around social status and utilitarian physical activity ${ }^{40}$ may also be impacting the level of political support for physical activity promotion in many of these settings.

The physical inactivity pandemic has been described as a "wicked" problem created and perpetuated by the complex system within which it occurs. ${ }^{41}$ Because the complex causes of physical inactivity are ingrained in many aspects of our life and in multiple systems, viable solutions are likely those that engage sectors outside of health. It was this systems approach that informed the development of the GAPPA by WHO. ${ }^{22}$ A brief review of the history of public health reveals that some of the field's major successes for disease prevention and control have resulted from synergistic efforts between the health and other sectors. John Snow was notably instrumental in containing the cholera outbreak in 19th century London. His work led to the identification and disablement of a contaminated public water pump responsible for the spread of disease in South London. ${ }^{42}$ More recently, the incidence of dental cavities has dramatically declined as a result of fluoridation of the water supply, ${ }^{43}$ salt iodization has essentially resolved iodine deficiency in many parts of the world, ${ }^{44}$ and neural tube birth defects are prevented with folic acid fortification of staple foods. ${ }^{45}$ Each of these cases highlights the essence of public health: operating across sectors and settings, beyond hospitals, clinics, and health departments, to preserve health and prevent disease and premature mortality in populations.

Increasing the global levels of physical activity demands that we return to the essence of good public health practice by implementing well-orchestrated, transformative, multisectoral strategies and avoiding health-centric approaches. This is evidenced by the cross-sectoral nature of the strategies proven to be effective for promoting physical activity at scale. ${ }^{9,18}$ In this article, we define physical activity promotion strategies as all approaches that have demonstrated effectiveness in increasing population-level physical activity. ${ }^{9}$ We base our definition on the "7 best investments for physical activity" of the Toronto Charter (Table 1). ${ }^{18}$

\section{Exploring the Links Between Physical Activity Promotion and SDGs: Evidence, Gaps, and Opportunities}

In this section, we identify which SDGs could plausibly benefit from at-scale physical activity promotion strategies as these strategies represent opportunities to elevate the importance of physical activity promotion across multiple sectors and systems. We draw information on the potential linkages between physical activity promotion strategies and SDG achievement from WHO's GAPPA and by consulting a group of global physical activity experts. We further examine, through a systematic scoping review of the literature, the extent to which the plausible benefits of physical activity promotion strategies on SDGs are supported by evidence. 


\section{Table 1 Examples of Scalable Strategies for Physical Activity Promotion Based on Findings by Reis et al ${ }^{9}$}

\begin{tabular}{ll}
\hline Physical activity strategy category $^{\text {a }}$ & $\begin{array}{l}\text { Scalable and effective examples of physical activity promotion strategies } \\
\text { from across the world }\end{array}$
\end{tabular}

1. Whole school programs

Finnish Schools on the Move is a national program in Finland. Schools and affiliated municipalities develop tailored action plans (adapted for schools and regions) and are effective in increasing physical activity throughout the full school day.

2. Active transport systems

BRTs provide high-speed, mass public transport, using buses running on segregated lanes and stopping at stations spaced further apart than traditional bus stops. BRTs are implemented in more than 150 cities worldwide, most in MICs (it started in Latin America), and are effective in promoting walking, bicycling, and public transit use.

3. Active urban design

Copenhagen, Denmark, is recognized as a Cycling City. The broad and connected urban design infrastructure and logistical, legislative, and cultural actions have proven effective in increasing cycling for transport and leisure in the city.

4. Physical activity promotion through primary health care

The Physical Activity on Prescription (FaR@) program from Sweden has built physical activity promotion into primary care systems. Through this program, qualified medical personnel deliver individually tailored prescriptions for physical activity for persons who are inactive or at risk of chronic diseases. The program has full integration into the electronic and operational aspects of the Swedish health care system. This program is effective in increasing physical activity among those seeking primary health care services.

5. Mass media campaigns

The 10,000 Steps Rockhampton program of Queensland, Australia includes a multitargeted mass media campaign for promoting physical activity through improved social support for disadvantaged groups. The project incorporates effective social marketing tools and has been effective in promoting physical activity engagement.

6. Community wide programs

Academia da Saude is a national program implemented by the Ministry of Health of Brazil. The program includes physical activity classes in rehabilitated public open spaces in low-income neighborhoods, health screening and counseling, and many other community-building activities in place-based settings (parks and plazas). This program has proven effectiveness in increasing leisure-time physical activity in disadvantaged neighborhoods.

7. Sports for all programs

Grassroots Soccer in South Africa is part of a global movement in sport for development. This program focuses on HIV/AIDS prevention and awareness and uses sports leagues as a means to achieve its goals.

\footnotetext{
Abbreviations: BRTs, bus rapid transit systems; MICs, middle-income countries.
}

aBased on "Best Seven Investments for Physical Activity" of the Toronto Charter.

The SDGs consist of 17 broad goals, described in aspirational language to resolve the major problems of the world in the 21st century (eg, SDG 1: "End poverty in all its forms, everywhere"). ${ }^{2}$ These 17 goals are further split into 169 more specific and tangible targets (eg, SDG Target 1.1: "By 2030, eradicate extreme poverty for all people everywhere, currently measured as people living on less than $\$ 1.25$ a day") and, finally, into 231 unique indicators. SDG indicators constitute the measurable benchmarks via which the UN tracks each country's progress toward fulfilling the 2030 global sustainable development agenda (eg, SDG Indicator 1.1.1: "Proportion of population below the international poverty line, by sex, age, employment status and geographical location [urban/rural]").

The WHO's GAPPA proposes plausible pathways of action through which physical activity promotion might help achieve targets for 13 out of the 17 SDGs. ${ }^{22}$ However, to date, plausible linkages between physical activity promotion strategies and SDG indicators have not been identified. To fill this gap, we invited a group of global physical activity experts to participate in a conceptual linkage exercise for systematically rating the plausibility of observing improvements in SDG indicators if the implementation of physical activity promotion strategies were to occur globally and at scale (ie, 1617 combinations of 7 physical activity best investments X 231 SDG indicators explored). Deductive logic was used to obtain inputs from topic experts. The pool of experts consisted of the authors of this article plus the authors and executive committee members of the Lancet Physical Activity Series III (36 global physical activity experts were surveyed of whom 33 [92\%] responded). The pool of respondents included national origin representation from all inhabited continents and area expertise in a wide array of topics and methods, including but not limited to exercise and sports sciences, measurement, surveillance, epidemiology, spatial analysis, complexity sciences, environmental sciences, childhood and adolescence, chronic disease prevention and control, behavioral science, disabilities, health disparities, global health, and policy.

Through this exercise, we identified plausible beneficial impacts of large-scale implementation of physical activity promotion strategies for 14 of the 231 unique SDG indicators, stemming from 6 of the 17 SDGs (see Supplementary Table S1 [available online]). The data collection, rating, and analysis process for the conceptual linkage, as well as additional detailed results, are available in the Supplementary Material (available online). The complete crosstabulation results of the 7 physical activity promotion strategies (best investments) with the 231 indicators by the 33 Lancet Physical Activity Series III authors who participated in this exercise are available at: https://doi.org/10.17605/OSF.IO/NB652.

The scoping review was conducted following Preferred Reporting Items for Systematic Reviews and Meta-Analyses (PRISMA) Guidelines. ${ }^{46} \mathrm{We}$ used systematic snowball sampling to identify relevant published articles reporting findings on the relationship between physical activity promotion strategies and SDGs. ${ }^{47}$ Eligible articles for data abstraction were original research manuscripts examining the effect of a physical activity promotion strategy on at least 1 SDG target beyond the known cardiometabolic and cancer health benefits of physical activity. ${ }^{5}$ The search terms used were consistent with those used in a previous scoping review examining physical activity promotion strategies 
implemented at scale, which was part of the Lancet Physical Activity Series II. ${ }^{9}$ In both of these reviews, the "physical activity promotion strategy/intervention" search terms were based on the framework of the 7 best investments for physical activity of the Toronto Charter. ${ }^{18}$

Ninety original research articles examining the effects of physical activity promotion strategies on SDGs were identified through the scoping review of which $73 \%(81.1 \%)$ were from HICs, $15 \%$ (16.7\%) from middle-income countries (MICs), and 2\% (2.2\%) from low-income countries (LICs). The scoping review methodology and descriptive statistics of articles meeting all inclusion criteria are available in the Supplementary Material (available online). The scoping review data abstraction table can be accessed at: https://doi.org/10.17605/OSF.IO/NB652.

When combining the information gleaned by the 3 sources (GAPPA, 33 global physical activity experts, and the systematic scoping review), possible benefits of physical activity promotion strategies were identified for 15 of the 17 SDGs (Figure 1). We also confirmed that all 7 best investments for physical activity may play a role toward the achievement of the UN sustainable development agenda. However, the most robust evidence currently available points toward best investments 3 (active urban design), 2 (active transportation policies), and 6 (community-based programs).
The SDGs identified as most relevant by the 33 global physical activity experts through the conceptual linkage exercise did not perfectly overlap with those previously identified in GAPPA. This is likely due to the levels of the UN sustainability agenda in which each linkage exercise operated (indicators vs targets). Understanding the plausible contributions of physical activity promotion strategies on both indicators and targets is informative and necessary. On the one hand, highlighting the SDG indicators that can benefit from at-scale physical activity promotion strategies can help integrate physical activity promotion as a key element of the sustainable development action plan for countries committed to the UN's established benchmarks. On the other hand, it is important to recognize that although physical activity promotion strategies may have limited or no impact on the UN-established indicators of a given goal, these strategies can still contribute directly toward achieving that SDG. SDG 13 (climate action) is one such example. GAPPA highlights plausible pathways of action via which physical activity promotion can meaningfully contribute to climate change mitigation and, hence, underlines its relevance for SDG 13.22 This is further supported by scientific evidence with $20 \%$ of studies identified in the scoping review reporting reductions in carbon emissions associated with motorized travel in cities, even though there is no SDG indicator that tracks emissions resulting from the motorized transport of people and goods in urban settings.

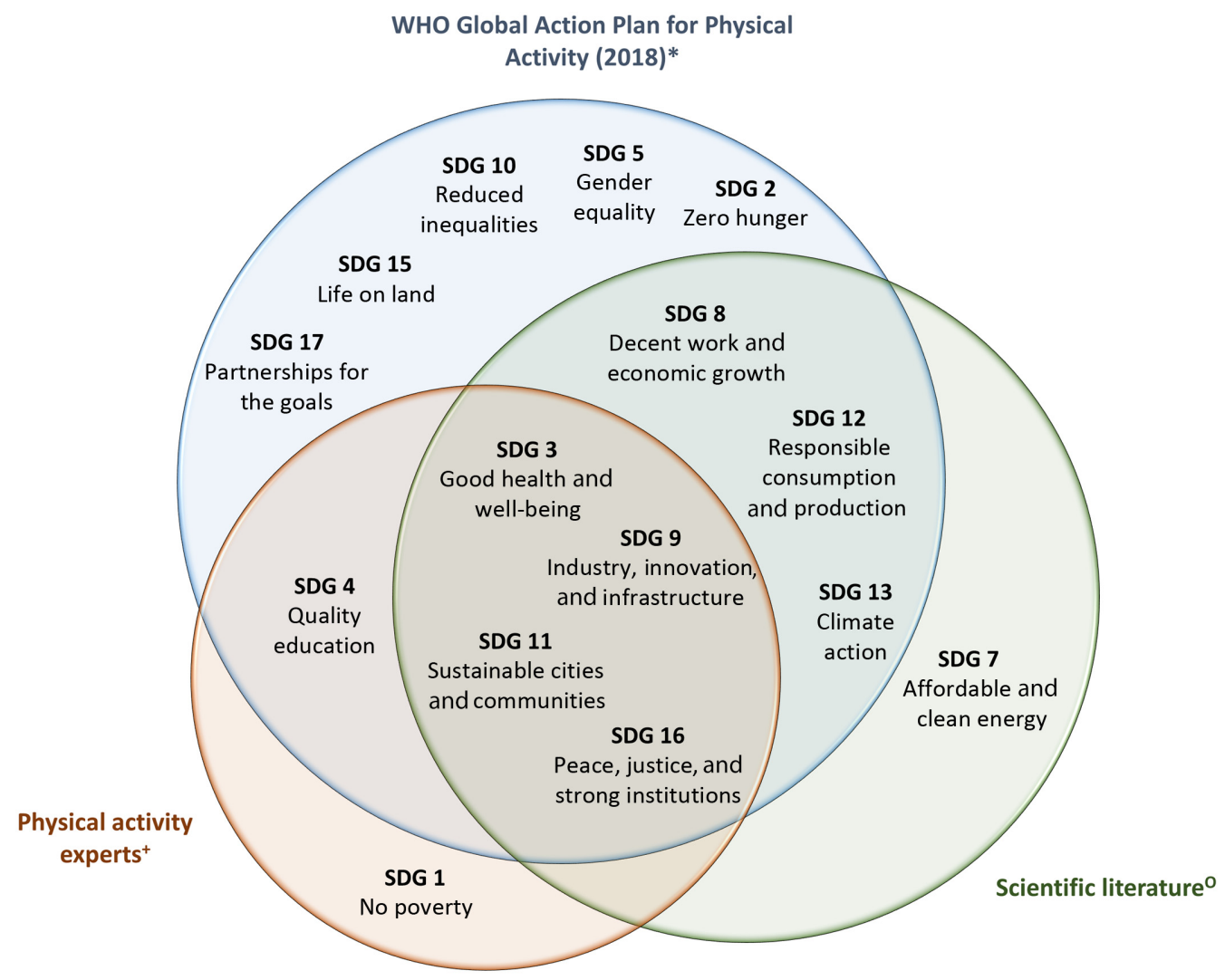

Figure 1 - United Nations SDGs that could benefit from at-scale physical activity promotion strategies: summary of plausible linkages and published research. *Based on Appendix 1 of the WHO Global Action Plan for Physical Activity, 2018, which poses plausible benefits of physical activity promotion for SDG targets. SDGs indicates Sustainable Development Goals; WHO, World Health Organization. ${ }^{+}$Based on the consultation of 33 global physical activity experts (article authors plus Lancet Physical Activity Series III authors and executive committee members, who identified plausible benefits of physical activity promotion for SDG indicators). ${ }^{\circ}$ Based on a systematic scoping review of the peer-reviewed literature; SDGs included are those for which at least 1 article reports statistically significant results suggesting a beneficial impact of physical activity promotion strategies on SDG targets. 
Furthermore, not all plausible links between physical activity promotion strategies and SDGs are currently supported by scientific evidence, highlighting important research gaps. Research efforts are needed to comprehensively quantify the potential benefits of at-scale physical activity promotion strategies on sustainable development. Some SDGs of particular relevance for future study are SDG 4 (quality education), which was identified as relevant both by GAPPA (target level) and by the physical activity expert group (indicator level), and those pertaining to the reduction of socioeconomic and gender-based inequalities (SDGs 10 and 5, respectively). These inequalities largely underpin current global patterns of physical inactivity ${ }^{48}$ and, particularly, observed differences across activity domains (ie, leisure-time vs transport- or work-based physical activity). ${ }^{49}$ Inversely, physical activity promotion could also become part of the solution for addressing global health and socioeconomic and gender-based inequalities. ${ }^{50}$ Table 2 explores the bidirectional relationship of physical activity and these inequalities and outlines the need for synergistic action to reduce physical inactivity and inequalities worldwide.

\section{Simulating the Impacts of Physical Activity Promotion Strategies on SDGs}

As evidenced by the results of the conceptual linkage exercise and scoping review, and by global policy guiding documents (GAPPA), the potential connections between physical activity promotion strategies and SDGs are numerous. However, the absence of robust experimental evidence on how these strategies could impact SDGs in different contexts when implemented at scale may undermine their recognition as viable solutions and their adoption by sectors outside health. To bridge this evidence gap, we applied agent-based modeling, a systems-oriented approach, ${ }^{61}$ to simulate the effects of large-scale physical activity promotion strategies on recreational and transportation-based physical activity and 6 SDG-related outcomes: road traffic deaths (SDG 3), transportation mode share (SDG 9), convenient access to public transport, levels of fine particulate matter, and access to public open spaces (SDG 11), and levels of carbon dioxide emissions (SDG 13).

In terms of the policy scenarios, we focused on physical activity strategies that increased access to, and the quality of, transport systems and public recreational spaces (best investments 2 and 3) while reducing inequalities in access (SDG 10). Furthermore, we addressed 2 additional gaps identified by the scoping review. First, we generated estimates for LMIC city types, which are relatively underrepresented in the scientific literature given the sparse data from these settings. Second, we estimated the effects of multisectoral actions combining multiple strategies.

Agent-based models simulate a composition of autonomous entities called agents. These agents "make decisions" according to a set of rules that guide their interaction with the surrounding environment and other agents over time. ${ }^{61}$ This method is particularly appropriate for exploring complex adaptive systems, such as cities, in which agents' (referred to as persons or people in our model) decisions and behavior are influenced by social and builtenvironment factors that are spatially distributed.

\title{
Table 2 Physical Activity and Global Health Socioeconomic and Gender Inequalities
}

\begin{abstract}
Inequalities remain among the biggest challenges for global physical activity promotion. It has been well documented that the poorest, girls and women, the oldest, and people with disabilities are among those least active during leisure time. Furthermore, there are substantial inequalities across other activity domains (ie, work, transport, and home) by race/ethnicity, geographic location, and occupation. ${ }^{5,13,14,48,51}$ These physical activity disparities lead to pronounced health and social inequalities, having direct relevance for SDGs 3 (good health and well-being), 5 (gender equality), and 10 (reduced inequalities).

The implementation of scaled-up physical activity promotion strategies may help in reducing global health (SDG 3), socioeconomic (SDG 10), and gender (SDG 5) inequalities. All physical activity promotion strategies that work at scale ${ }^{9}$ can play an important role for achieving reductions of inequalities. These strategies are embedded within structures and systems affecting the equitable distribution of, and access to, resources and services in communities across the globe. The promotion of equity can happen at schools (PA investment 1); through robust, safe, and efficient transport systems (PA investment 2); through urban design practices grounded in active living principles (PA investment 3); through effective health care systems that prioritize disease prevention and healthy lifestyle promotion (PA investment 4); through good communication strategies (PA investment 5); through comprehensive community action (PA investment 6); and by promoting sports and recreation for all (PA investment 7). For instance, some programs delivering free physical activity classes in the community and building safe and equipped spaces located in socially deprived areas, and which embed these actions within public health policies (community-based approaches, best investment 6 ), have significantly attracted more women than men ${ }^{52,53}$ and have effectively increased social capital and safety in the community. ${ }^{54}$

However, focusing exclusively on identifying and prioritizing populations at high risk for physical inactivity may not be sufficient for reversing global inequalities. To truly achieve this, the systemic, underlying factors preventing some population groups from accessing resources and opportunities for physical activity must be addressed. ${ }^{4}$ Hence, a comprehensive, system-wide shift must become a priority. Such an approach would also help avoid the unintended consequences of rolling out seemingly innovative solutions to addressing the physical inactivity pandemic, ${ }^{55}$ such as only reaching economically advantaged members of society (inverse equity hypothesis) ${ }^{56}$ or distributing resources where population needs are already being met (inverse care law). ${ }^{57}$

The relation between the physical activity promotion and sustainable development agendas is not unidirectional. Hence, improvements in SDGs 10 (reduced inequalities) and 5 (gender equality) could lead to improvements in population levels of physical activity. There are successful examples in physical activity and other realms of public health demonstrating that when economic, educational, and gender-based barriers are removed, successful health outcomes can be achieved. ${ }^{58-60}$

Given the bidirectional nature of physical activity promotion and inequality reduction goals, adopting a synergistic approach for action represents a win-win opportunity and our best chance for advancing the global physical activity and equity agendas. A paradigm shift for physical activity is required in which sedentary behaviors are discouraged and physical activity becomes the norm for all. This will require moving away from the current operating model in many LMICs and among economically disadvantaged communities where, due to a lack of opportunities and resources, many engage regularly in necessity-driven physical activity for transport and work in unsafe, unenjoyable, undignified, and unsustainable conditions. ${ }^{38,40}$ Instead, we should focus on making the physically active option of all daily activities the default choice for all groups by making it the easiest, most convenient, cheapest, safest, and most enjoyable option. , $^{4,49}$
\end{abstract}

Abbreviations: LMICs, low- and middle-income countries; PA, physical activity; SDGs, Sustainable Development Goals. 
The model is described briefly in the following section, and technical details-including implementation details and information concerning parameters, input data, data sources, and sensitivity analyses - and the complete list of limitations are provided in the Supplementary Material (available online). The model and all accompanying files can be accessed via the following link: https://doi.org/ 10.17605/OSF.IO/NB652.

\section{Modeling Changes in Cities and People Over Time}

We modeled 3 types of cities: a sprawling, car-dependent city in a HIC; a large city in a MIC; and a city in a LIC (Figure 2). We used information from real-world cities to inform the characteristics of each city type, including income distribution; spatial distribution of jobs, public and private places for recreational physical activity, and other destinations (such as restaurants, shops, and markets); and coverage and quality of road, walking and cycling infrastructure, and public transportation systems (Supplementary Table S4 and Section 3.3.3.1 [available online]). These cities do not represent any specific city, rather, they are abstract representations of common city types in HIC, MIC, and LIC. Notably, the HIC city type in our model is not intended to represent the classic compact, dense, and connected European city. Rather, it was designed to resemble sprawling cities like those typically found in the United States and Canada with high car dependence and low public transit and active travel infrastructure coverage.

Each time step in the model was equivalent to 1 week in the real world, a timeframe frequently used for investigating physical activity behavior. The model was run for a period equivalent to 10 years.

Each city type was modeled with 1000 agents representing adult residents. An income level was assigned to each person according to their residential location in the city (Figure 2). Their residential location also determined the number, accessibility, and quality of public and private places for recreational physical activity in their surroundings, distance to work, and coverage and quality of transit infrastructure. Income level was used to probabilistically determine each person's vehicle (car, motorcycle, and bicycle) ownership. Moreover, each person was assigned a group of friends, which composed their personal social network.

We simulated decision making that resulted in 2 behaviors that were shaped by a set of individual, interpersonal (social norms and personal social network), and environmental factors (see Supplementary Figure S3 [available online]). First, persons decided whether they were going to engage in recreational physical

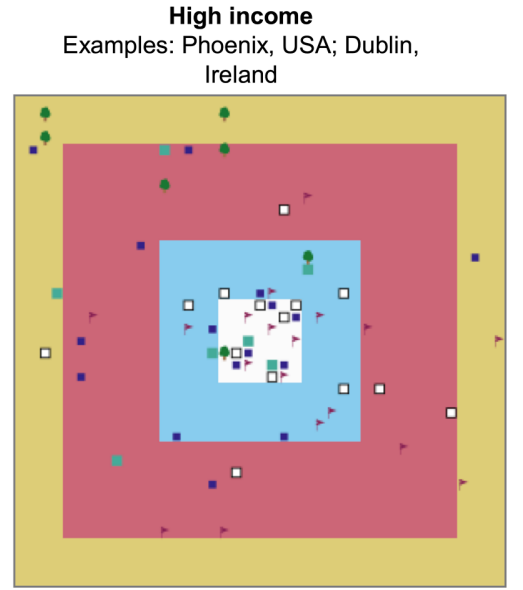

A large sprawling city characterized by medium income inequality and low-to-medium population density. Lowincome populations tend to reside in or close to the city center while wealthier groups largely reside in the city's periphery. The city center has a greater concentration of jobs, private spaces for recreational physical activity, and places for social interaction than peripheral areas of the city. The city has a well-connected road network, good public transportation coverage (less so in highincome regions), quality and service frequency. It also has good walking infrastructure, but the cycling network is concentrated in downtown. Car is the dominant mode of transportation. The city has relatively low levels of air pollution and usually high risk of road traffic fatalities (due to high car use and sprawl). A large proportion of the population engages in recreational physical activity at least once per week.

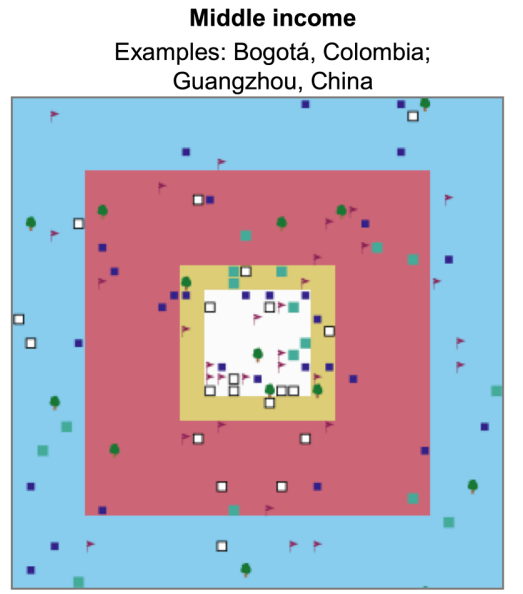

It is characterized by high income inequality and medium-to-high population density. High-income populations tend to reside in or close to the city center while lower income groups largely reside in the city's periphery. The city center has a greater concentration of jobs, spaces for recreational physical activity, bicycle infrastructure, and public transportation options. The city has a well-connected road network and generally good walking infrastructure except for in low-income areas, where both coverage and quality tend to be poorer than in the city center. Car and public transportation tend to be the dominant modes of transportation. The city has medium levels of air pollution and risk of road traffic fatalities. Less than half of the population engages in recreational physical activity at least once per week.



A densely populated city with high income inequality. High-income populations reside in the periphery while low-income groups tend to cluster in the center. Employment and public transportation are concentrated near the center. Spaces for recreational physical activity are mostly private and peripheral. The city has a sparsely connected road network with poorer coverage in low-income areas. Bicycle facilities are largely non existent while walking infrastructure is patchy in the center and largely nonexistent or of poor quality in other areas. Despite this, many residents, particularly those in the low- and middle-income groups, walk as their primary mode of transportation. Public transportation is the second most used mode. Car use is mainly among highincome populations. The city has high air pollution and medium rates of road traffic fatalities. A small fraction of the population engage in recreational physical activity at least once per week.
High-income area Activity middle-income area Activity low-income area Downtown
Public spaces for recreational physical activity Private spaces for recreational physical activity Workplaces

Places for social interaction (restaurants, shops, malls, etc.)

Public transportation

Figure 2 - Characterization of 3 city types represented in the agent-based model. Further details provided in the Supplementary Material (available online). See online article for color version of figure. 
activity or not. Second, they decided the modes of transportation they were going to use to commute to 3 types of destinations: (1) to work; (2) to recreational physical activity spaces; and (3) to up to 20 other destinations, such as restaurants, shops, and markets (Table 3 and Figure 3 ). The decision making underpinning people's behavior was based on elements of the discrete choice theory, ${ }^{62}$ opinion dynamics, ${ }^{63,64}$ and the multilevel theory of behavior. ${ }^{65}$

Engagement in recreational physical activity was probabilistically modeled each week by having people consider their intrinsic level of intention and the accessibility and quality of spaces for recreation in their neighborhood. This intention for physical activity was updated each week based on the person's past behavior, the behavior of their personal network, and the broader community. ${ }^{66,67}$ If the person decided to engage in recreational physical activity during a given week, a weekly frequency was assigned (see Supplementary Section 3.3.4.2 [available online] for further details).

The most appealing mode of transportation (walking, bicycle, mass transit, car, or motorcycle) for each of the destinations mentioned earlier was determined by considering a range of factors, including vehicle ownership, travel distance, relative cost, person's past travel pattern, travel pattern of their social network and the broader community, and coverage and quality of transit infrastructure in their neighborhood (see Supplementary Section 3.3.4.3 [available online] for further details). Travel patterns were recorded every week, and modes of transportation were reevaluated every 4 weeks.

Weights assigned to capture the importance of each factor considered in the persons' decision-making process for recreational physical activity were derived from Garcia et al. ${ }^{68}$ Specifically, a person's past behavior and the quality and accessibility of spaces for physical activity were assumed to have the greatest influence on decision making, followed by the behavior of the personal network and then that of the community at large. For travel behavior, the same weight was assigned to each factor. Details on the weights and other parameters can be found at https://doi.org/10.17605/ OSF.IO/NB652.

We tested the extent to which the model's outcomes were sensitive to uncertainty in the weights assigned to each factor considered in the people's decision-making process, using expected value of partial perfect information. ${ }^{69,70}$ These analyses suggested that population levels of recreational physical activity were sensitive to the weight given to own past behavior (most strongly in the HIC and MIC city types). Transportation mode share and consequent health and environmental impacts showed low (in most cases) to moderate sensitivity to weights assigned to own past travel behavior and travel time, quality of transit infrastructure (highest sensitivities observed in MIC and LIC city types), and travel cost (HIC city type). See Supplementary Section 3.6 (available online) for further details on sensitivity analysis methods and results and Supplementary Section 3.3.3 (available online) for more details on model calibration.

\section{Scenarios}

We simulated 6 scenarios per city type for a total of 18 modeled scenarios (Table 4). These included a baseline or "business-asusual" scenario and 5 large-scale physical activity promotion strategies $^{18}$ aimed at reducing inequalities, aligned with SDG 10 in: (1) access to public transit (best investment 2: active transport systems), (2) public recreation spaces (best investment 3: active urban design), (3) walking and cycling infrastructure (best investments 2 and 3), (4) a combination of all strategies, and (5) a combination of all strategies with an increase in the cost of driving. Socioeconomic inequalities (SDG 10) were reduced by, first, expanding and improving the recreational and transport infrastructure in the best-serviced income group in the business-as-usual scenario and, then, by affording the same conditions for all other people. All strategies were implemented at the end of year 2. One-hundred repeated runs were simulated for each scenario, a number determined by the results of a consistency analysis (more details in Supplementary Section 3.5 [available online]).

\section{Simulation Results}

The simulation results are summarized in Figure 4 and Supplementary Table S8 (available online). Following, we describe the main patterns observed in each scenario.

In the public transport scenario (best investment 2), reducing spatial inequalities in coverage and quality of public transport infrastructure resulted in improved access to public transport in all city types (SDG 11), with the sprawling, car-dependent HIC city type experiencing the most radical transformation. However, minimal changes in public transport trips and car use were observed in this city type. In contrast, increases in public transport use and concurrent decreases in car and motorcycle trips were observed in LIC and MIC city types (SDG 9). In all city types, the gains in public transport commuting were concurrently associated with a reduction in bicycle trips. Road deaths (SDG 3) were reduced in all city types, though most notably in the LIC city type. Reductions in fine particulate matter (SDG 11) were observed in the MIC city type with only marginal changes in the LIC and HIC city types. Changes in carbon dioxide emissions (SDG 13) mirrored changes in transportation patterns with significative relative reductions in carbon dioxide emissions observed in MIC and LIC city types.

In the public recreational spaces scenario (best investment 3), access to open spaces for public use (SDG 11) increased and inequalities in access to these spaces were reduced in all city types. This led to increases in recreational physical activity (SDG 3), particularly in the LIC city type, which had the lowest baseline levels for this behavior. In the LIC city type, new trips to recreational physical activity spaces were done mainly via public

\section{Table 3 A Week in the Life of an Agent}

Cristina lives in a large city in a middle-income country, and 2 years ago, she moved to one of its middle-class neighborhoods a few kilometers away from the city center. She has a full-time job and commutes every workday by bus even though she owns a car-she feels that the public transport service is quite good and reliable in her region, and it has been her travel mode to work ever since she moved there. Cristina enjoys exercising. She would love to have a green park with a track nearby where she could go jogging after work, but unfortunately, the only park in the neighborhood is not well kept and is dark at night. Thus, Cristina and her friends go to one of the local private gyms for their exercise, usually by walking. Cristina will jog only twice this week, though, as she is going to be quite busy during the other days. A friend of hers is going to celebrate her birthday in a restaurant in the city center to which Cristina will go with her car. Cristina also needs to do her grocery shopping and, again, will use her car for carrying the goods. On the weekend, she will watch the latest science fiction movie with some friends in a cinema not so far away from home, so they plan to get the bus to go there. 


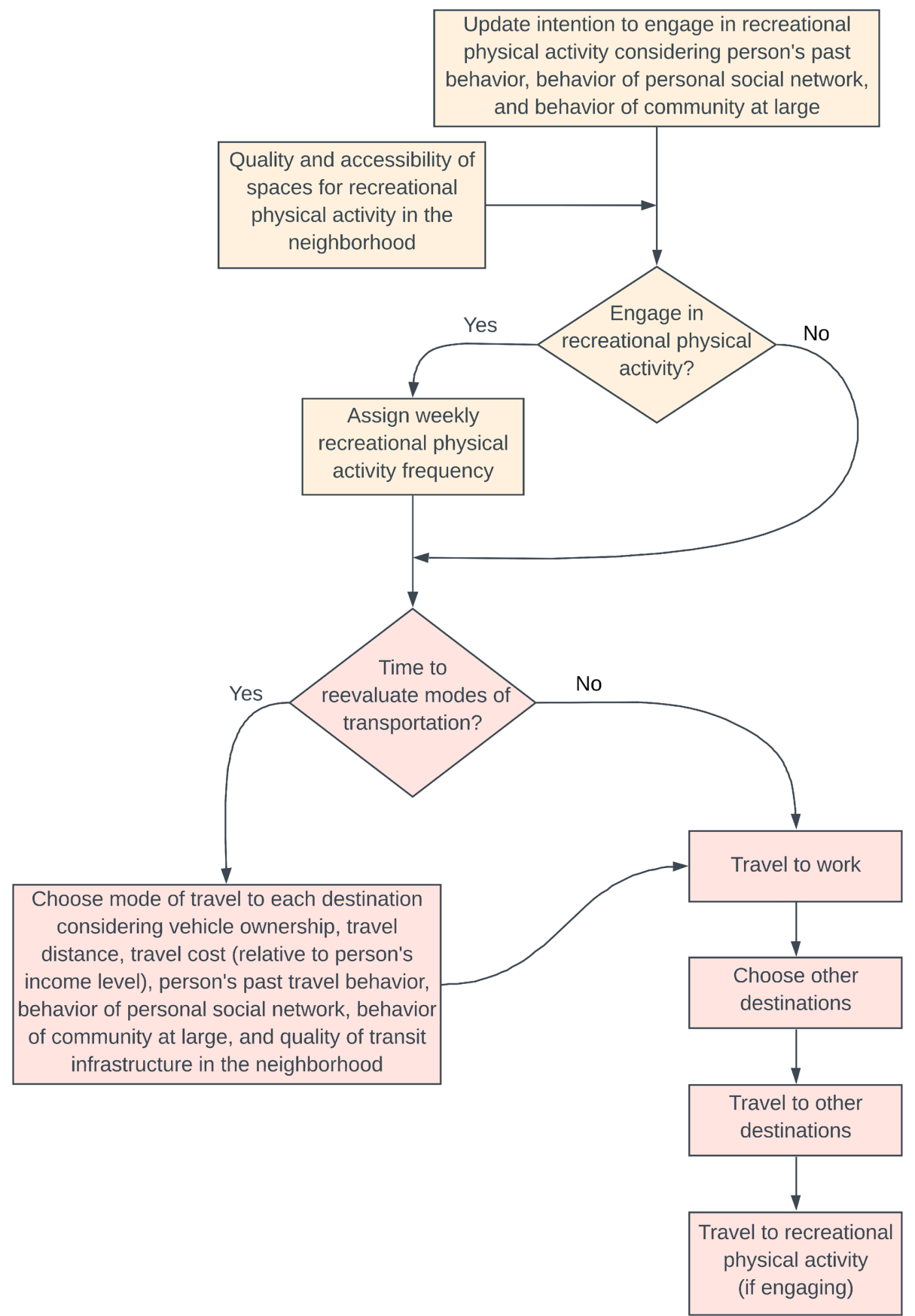

Figure 3 - Overview of the agents' decision-making process. The decision steps for recreational physical activity are shown in yellow and those for travel behavior are shown in red. The process is repeated every week (ie, one time step). Re-evaluation of the modes of transportation occurs every 4 weeks. See online article for color version of figure.

transport, leading to an increase in the percentage share of public transport trips, a concurrent decrease in the proportion of trips by other modes (SDG 9), and reductions in carbon dioxide emissions (SDG 13).

In the walking and cycling infrastructure scenario, with reductions in spatial inequalities in the coverage and quality of cycling and walking infrastructure (best investments 2 and 3), substantive changes in travel patterns (SDG 9) were observed in the LIC and MIC city types and only marginal changes in the HIC city type. In the LIC and MIC city types, improvements in infrastructure were most effective in increasing walking trips. Reductions in car and motorcycle use were observed in the MIC city type and in public transport use in the LIC city type. Road deaths increased in the LIC city type, whereas they reduced in the sprawling, cardependent HIC city type (SDG 3). Reductions in fine particulate matter (SDG 11) as well as carbon dioxide emissions (SDG 13) were observed in the MIC city type.

The scenario combining all strategies (best investments 2 and 3) was more effective than the sum of each strategy alone, particularly in LIC and MIC city types, suggesting a synergistic effect. In the LIC and MIC city types, substantive reductions in car and motorcycle use were observed, paralleled by increases in walking trips and public transport 


\section{Table 4 Simulation Scenarios for Scaled-Up Physical Activity Promotion Strategies}

1. Public transport scenario (best investment 2-transportation systems prioritizing active travel and transit use): Reduction in inequalities in coverage and quality of public transport infrastructure and service frequency (eg, creation of bus rapid transit infrastructure to improve access in poorly connected neighborhoods).

2. Public recreational spaces scenario (best investment 3-urban design to promote transport and recreational physical activity): Reduction in inequalities in the spatial distribution and quality of public spaces for recreational physical activity (eg, creation of parks with physical activity facilities).

3. Walking and cycling infrastructure scenario (best investments 2 and 3): Reduction in inequalities in coverage and quality of cycling and walking infrastructure (eg, creation of wide sidewalks throughout the city and a comprehensive bicycling path network).

4. All physical activity promotion scenarios combined: Scenarios 1 to 3 combined

5. All scenarios combined and increasing cost of car trips: Scenarios 1 to 3 combined and increase in the costs of car trips. Although not a physical activity promotion strategy, increasing the cost of car trips to disincentivize car use (in the form of fuel tax or higher vehicle registration, vehicle cost, or parking fees, for instance) is closely related to active travel promotion and is a policy alternative with the capacity to act synergistically with the traditional physical activity promotion strategies represented in simulated scenarios A to C.

use (SDG 9). Notably, the combination of strategies offset reductions in public transport use and walking that were observed when improvements in active travel and public transport systems were implemented in isolation (SDG 9). Significant reductions in road traffic deaths (SDG 3), fine particulate matter (SDG 11), and carbon dioxide emissions (SDG 13) were observed in the MIC and LIC city types, whereas in the HIC type, only road deaths reduced significantly.

The scenario combining all strategies (best investments 2 and 3) plus increases in driving costs resulted in steep declines in car use and increases in walking trips in all city types. The HIC and MIC city types also experienced a rise in bicycle and public transport use (SDG 9). Furthermore, reductions in road deaths were predominantly observed in LIC and MIC city types with only modest decreases noted in the sprawling, car-dependent HIC city type (SDG 3). Reductions in fine particulate matter were also observed, particularly in the MIC city type (SDG 11). Moreover, significant reductions in carbon dioxide emissions (SDG 13) were observed in the HIC city type. Under this scenario, MIC and LIC city types similarly experienced sizable reductions in carbon emissions relative to baseline levels.

\section{Physical Activity Promotion for Health and Sustainable Development}

We examined the evidence through the identification of plausible benefits for SDGs from large-scale physical activity promotion strategies (GAPPA and expert consultation), a scoping review to determine which plausible links were supported by evidence and where research gaps were, and a simulation model to test the potential impacts of physical activity promotion strategies on SDGs in 3 types of cities. Our findings demonstrate some symbiotic relationships between physical activity and the UN sustainable development agenda. This synergy presents untapped opportunities for jointly advancing global physical activity promotion efforts and SDG attainment.

\section{Physical Activity Promotion for Health}

Our results suggest that the population health benefits of physical activity promotion are larger than previously estimated. In addition to the known benefits for noncommunicable disease prevention, 5,71 physical activity promotion can also help reduce road traffic deaths, decrease the morbidity and mortality caused by air pollution, and improve mental health.

However, these new insights do not unveil all the potential benefits that physical activity promotion may have for population health. Although all 7 best investments for physical activity are plausibly linked to expected improvements for SDG 3 (good health and well-being) beyond chronic disease prevention, our scoping review revealed that studies examining the noncardiometabolic and cancer-related health effects of best investments 1 (whole of school approaches), 4 (physical activity promotion in primary care), 5 (mass media campaigns), and 7 (sports-for-all programs) remain lacking. Producing evidence on the additional health benefits of atscale physical activity promotion will require robust transdisciplinary collaborations with experts outside of the health sector. Notably, more than half $(57.8 \%)$ of studies identified via the scoping review were published in nonhealth journals, underscoring the importance of cross-sectoral collaboration.

\section{Physical Activity Promotion for Sustainable Development}

Physical activity promotion strategies have demonstrable benefits for SDGs, and our results suggest that they could become an integral part of the action plan for achieving SDGs 3 (good health and well-being), 9 (industry, innovation, and infrastructure), 11 (sustainable cities and communities), 13 (climate action), and 16 (peace, justice, and strong institutions). Additional SDGs may benefit from at-scale physical activity promotion strategies, but more evidence is needed to confirm their impact (Figure 1).

The simulation results provide new insight into the potential context-specific consequences of physical activity promotion strategies for both physical activity and SDG outcomes. Urban and sociodemographic context matters when determining which solutions are the best suited for different global settings, and our results suggest that the effect of any intervention strategy is likely to vary across different urban typologies.

The synergistic implementation of physical activity promotion strategies shows tangible benefits for LIC, MIC, and sprawling HIC city types both in terms of physical activity participation and SDG improvements. However, cities in LMICs may stand to gain more from scaled-up, synergistic physical activity promotion strategies than sprawling, car-centric city types in HIC. The scenario combining all strategies yielded the greatest gains in recreational physical activity (SDG 3) in LIC cities, with lower, yet important, gains observed in the 2 other modeled city types. Meanwhile, positive shifts toward active and sustainable travel (ie, lower car dependence and more active forms of travel like walking, cycling, and transit-SDGs 3, 9, and 13) were most pronounced in the MIC city type. Under this scenario, significant relative reductions in carbon dioxide emissions were observed for the LIC and MIC city 

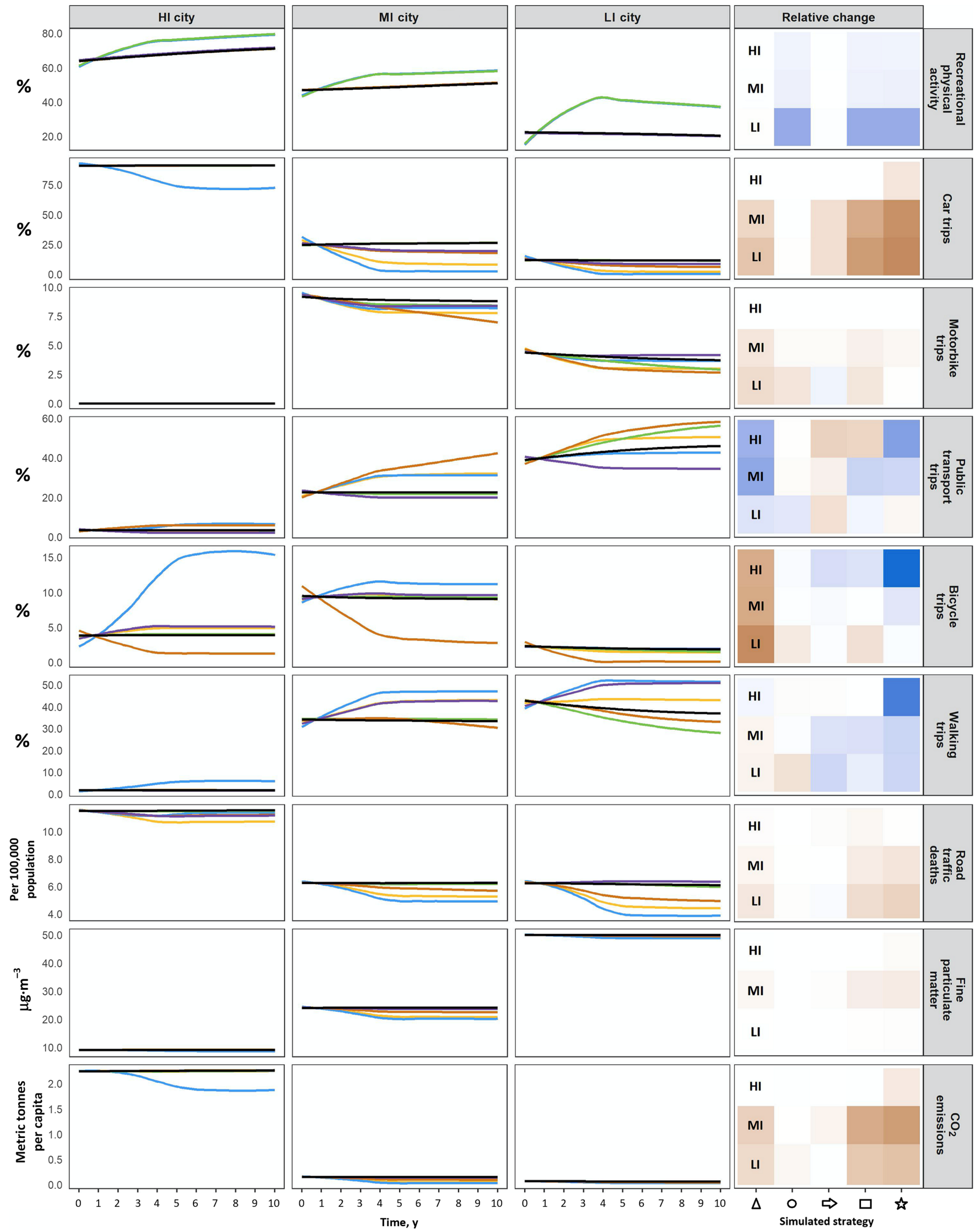

Simulated physical activity promotion strategies
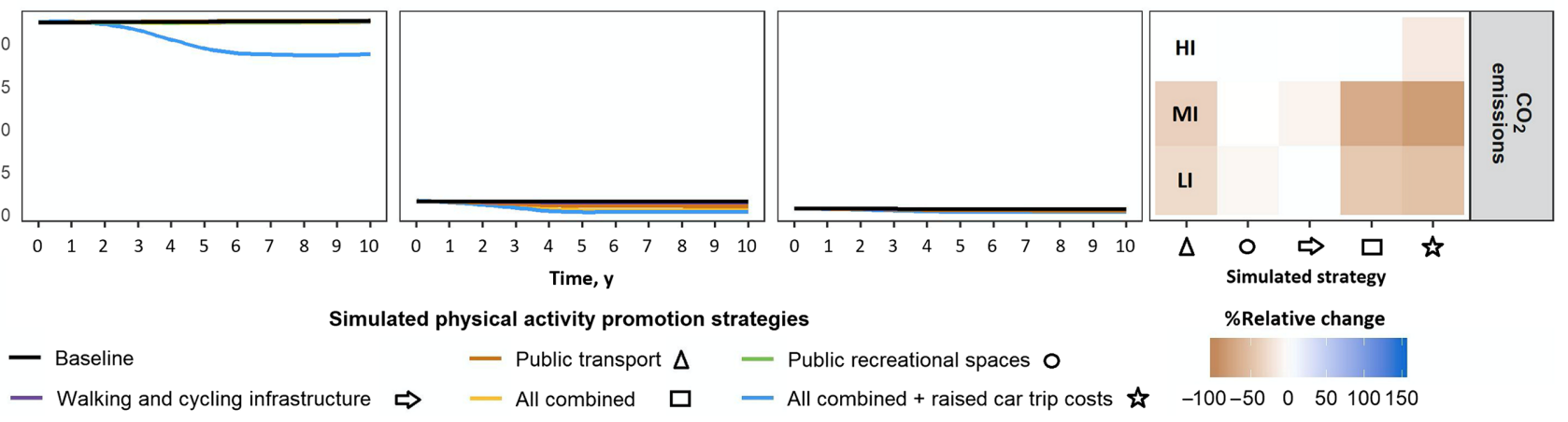

\%Relative change

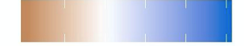

Figure 4 - Simulated trajectories in recreational physical activity and SDG indicator outcomes in LI, MI, and HI city types over 10 years by physical activity promotion strategy. The heatmap shows the percentage relative change in these outcomes at 10 years, for each city type, by physical activity promotion strategy. The carbon dioxide estimates encompass car, bus, and motorcycle emissions, whereas the estimates for fine particulate matter were modeled considering all sources. HI indicates high income; LI, low income; MI, middle income; SDGs, Sustainable Development Goals. See online article for color version of figure. 
types. On the other hand, gains in active transportation and reductions in carbon dioxide emissions in the modeled HIC city type with high car dependency were only observed when costs of driving were increased.

Disincentivizing driving can be a complementary strategy to maximize the effectiveness of physical activity promotion through expanded infrastructure for active travel and public transit ${ }^{72}$ and is a key element for climate change mitigation. In settings where car dependence is high and cities are locked in a rigid configuration, these strategies could become an essential part of the solution for addressing physical inactivity, air quality issues, traffic-related deaths, and climate change (eg, in most US cities, over $90 \%$ of trips are by car, and light-duty vehicles account for $16.5 \%$ of all greenhouse gas emissions). ${ }^{72-74}$ Higher costs of driving could be achieved via fuel taxes, higher parking costs and low spatial allocation for driving and parking, car sales taxes and car registration fees, congestion pricing, or removal of subsidies for highcapacity road construction. Some evidence supports that such policies are responsible for differences in transportation mode share across different typologies of high-income settings. ${ }^{72,75}$ In addition, more radical transformations in other aspects of the urban fabric, such as major zoning reconfigurations (best investment 3), are likely also needed to shift the prevalence of motorized travel toward more active, sustainable mobility.

Our results highlight the importance of investing in urban mobility to attain the best overall outcomes, which will likely require careful consideration of the dynamic interaction between the built and social forces and user habits in different global settings. A systems approach is recommended in this decisionmaking process to minimize the risk of unintended impacts on SDG attainment. This is exemplified in our model by the unintended decreases in active travel observed when the public transportation strategy was introduced in cities with low coverage of walking and cycling infrastructure and is further highlighted by the recent updates to the US Community Guide. ${ }^{76}$ Importantly, our model indicates that even after substantial large-scale changes, benefits for physical activity and SDG outcomes can take 5 or more years to manifest. These timeframes are notably longer than the time horizons within which funding, research, and public policy cycles usually operate.

\section{Building Evidence for Health in All Policies}

The results presented here are critical for raising awareness on the importance of including health in all policies and align with WHO's priorities for the next decade, which include "elevating the importance of health in the climate debate" and "earning public trust" through better dissemination of evidence-based solutions to global health priorities. ${ }^{77}$ Credible data are essential for bringing important issues to the forefront of the public agenda, ${ }^{77}$ which in turn, can raise demand for policy action. Our summary represents the best available evidence supporting the inclusion of physical activity promotion strategies as part of local and global sustainable development action plans.

However, the scoping review revealed a stark mismatch between the sources of evidence and where it will need to be applied: $80 \%$ of the articles stem from HICs, but $90 \%$ of the world's population lives in LMICs. ${ }^{78}$ LMICs also bear the highest disease burden from physical inactivity ${ }^{6}$ and are disproportionately affected by climate change, inequalities, poverty, and war-issues that the SDGs are designed to tackle. Our modeling results emphasize that the effects of physical activity promotion strategies can vary widely across contexts. Therefore, to inform locally relevant physical activity promotion and sustainable development action plans in LMICs, more research from these settings is needed.

Nonetheless, research alone will likely be insufficient for embedding health in all policies across global settings. Research should be planned and conducted with translation and dissemination in mind to ensure that the evidence on the synergy between physical activity, public health, and sustainable development is visible, accessible, understandable, and relevant to decision makers and the public.

\section{Synergistic Physical Activity Promotion and SDG Action}

The evidence from the different components of our study support the use of a synergistic approach to physical activity promotion and sustainable development-a result that aligns well with SDG 17 (partnerships for the goals). However, our findings suggest different avenues of synergistic policy action for LMIC cities and car dependent, sprawling HIC cities.

In LMICs, where there is often reluctance to address major societal and planetary challenges like improving air quality, enhancing road traffic safety, or mitigating climate change if such actions are considered to compromise economic development, substantial physical activity and SDG benefits can result from synergistic action. Many of the synergistic strategies (eg, increasing availability of and reducing inequalities in access to parks, walking and bicycling infrastructure, and public transit) are effective and relatively inexpensive ${ }^{79-82}$ and should be viewed as investments for creating healthy, safe, equitable, vibrant, and sustainable cities. ${ }^{12}$ Some cities around the world, including some in Europe (where most cities are nonsprawling and not overly car dependent) and a few Latin American cities, are good examples of the feasibility of synergistic action for physical activity promotion and sustainable development (Table 5). ${ }^{12,83}$

Sprawling, car-dependent HIC cities, on the other hand, are responsible for a large portion of the global demand for energy and are major contributors of carbon emissions of which a substantial portion can come from cars. ${ }^{74,88}$ According to our model, in these types of cities, physical activity promotion strategies that do not disincentivize car dependence and driving may only confer modest improvements in population-level physical activity and climate change mitigation but could, nonetheless, have positive impacts on local air quality and traffic-related deaths. It is important, however, to recognize that public health and sustainability evidence alone may not be sufficient for tipping the scale in favor of policies aiming to disincentivize car dependency. Because cars are embedded in the built and social fabric of so many cities, ${ }^{89}$ implementing these types of policies may carry a high political cost. Hence, adopting a trans-sectoral, systemsbased approach, with strategies for changing the social desirability of cars and actions aimed not only at making driving less appealing but also at making the healthier and more sustainable mobility options more attractive, will be essential for success. Although more evidence is required to understand which strategies are most effective in disincentivizing driving, immediate public health action can be informed by successful analogs from other fields (eg, taxes on cigarettes and sugar-sweetened beverages, strict locational restrictions for smoking, high-reach educational campaigns, etc) ${ }^{90,91}$ and by the recent experience of some cities in creating car-free zones while expanding their active travel and public transport infrastructure (Table 5). 


\section{Table 5 Real-World Examples of the Successful Implementation of Synergistic Approaches for Physical Activity Promotion and Sustainable Development}

Many urban development initiatives are synergistic, resulting in physical activity promotion as well as contributing to SDGs. There are real-world examples wherein the urgency to address the physical inactivity pandemic and of attaining the SDGs has led to the enactment of synergistic approaches, raising both public awareness and political will to act.

For example, in Mexico City (MIC setting), many recent initiatives, such as a fast-growing bus rapid transit system, a large-scale, publicly subsidized bicycle-sharing program, a comprehensive park rehabilitation program, a weekly open-streets event (Ciclovia), and the creation of several car-free downtown corridors, were implemented to improve mobility (SDG 9), air quality (SDG 11), health, and quality of life (SDG 3 ). ${ }^{12}$ All of these initiatives are likely to increase physical activity (best investments for physical activity 2 [active transport systems], 3 [active urban design], and 6 [communitywide approaches]).

There are also examples from high-income countries, with Europe leading the way, on the successful implementation of a synergistic agenda for physical activity and SDGs. Copenhagen, the capital of Denmark, aims to be the world's first carbon-neutral capital city (SDG 11). The ambitious 2025 Copenhagen Climate Plan builds on a mobility strategy with a goal of having $75 \%$ of all trips in Copenhagen made on foot, by bike, or by public transport (SDG 9). ${ }^{84}$ This mobility strategy will have a significant impact on population levels of physical activity (SDG 3) as well as on reducing energy consumption and greenhouse emissions (SDG 11). The Copenhagen public health strategy "puts the Copenhagener and everyday life at the center of health promotion, for example by making it attractive to cycle" (SDG 3). ${ }^{85}$ Thus, we see an example of synergy between the public health and climate change mitigation plans and goals.

With a similar vision to the Mexico City and Copenhagen examples, but on a larger scale, the EcoMobility Alliance is a network of 23 ambitious cities on 5 continents committed to building a sustainable mobility future that is efficient, people centered, low emission, and environmentally friendly. ${ }^{86}$ The EcoMobility Alliance has specifically identified transport and health as one of 8 program areas of focus, linking the public health benefits of active transportation to its environmental benefits. ${ }^{87}$

These real-world examples illustrate how common targets for synergistic action for physical activity promotion and sustainable development can be achieved (increasing global levels of physical activity; reducing air pollution and its health consequences; reducing traffic injuries; improving access to sustainable transport by all; increasing equitable access to green space; and mitigating climate change by reducing car dependency).

Abbreviations: MIC, middle-income country; SDGs, Sustainable Development Goals.

\section{Limitations}

The results presented in this article should be interpreted in light of the limitations of the methods employed. The conceptual linkage exercise was limited to 33 global physical activity experts. It is possible that a different pool of experts would have reached somewhat different conclusions. As is the case with any scoping review, the intent was to acquire a broad sense of the state of the science rather than an exhaustive list of all articles published on physical activity promotion and SDGs or a comprehensive assessment of the quality of each study. Only English language articles were included in the scoping review. Because the scoping review process involved abstracting data on potential relationships between 7 best investments (physical activity promotion strategies) and 169 SDG targets (ie, 1183 possible combinations), some pragmatic decisions were made to keep the search and abstraction process manageable. Expanding the search to include full-text mentions of the search terms, or expanding the pool of search terms, would have yielded additional results. In terms of the agent-based model, 3 general city typologies were modeled. The results should not be interpreted as being representative of any real-world city. Some realworld city types were not represented by any of the typologies of our model, including European and Australian cities. People's decisionmaking frameworks and weightings may differ across cities in HIC, MIC, and LIC and between people within the same city according to, for instance, cultural and economic factors, which our model did not account for. The sensitivity analysis suggests that population levels of recreational physical activity were sensitive to uncertainty in the weight of influence assigned to a person's own past behavior, particularly in HIC and MIC city types. Transportation mode share and consequent health and environmental impacts were less sensitive to uncertainty in assigned weights. It is noteworthy that parameters for which no reliable data were available were calibrated in the business-as-usual scenario. Although we included several SDG outcomes and tested multiple at-scale physical activity promotion scenarios, there are additional SDG outcomes and policy scenarios of relevance that were not included. Finally, this article examined possible benefits of physical activity promotion for SDG achievement. The relation between physical activity and SDGs is likely bidirectional, and future research should explore the impact of SDG achievement on population levels of physical activity. Additional technical limitations for each method are described in the Supplementary Material (available online).

\section{Conclusions}

Physical activity promotion and meeting some of the SDGs are strongly linked conceptually and supported by solid evidence. The simulation result of most relevance to our overall conclusions is that for "all strategies combined." This will not be a surprise to those familiar with public health strategies for addressing health behaviors at the population level. In virtually every case, real population-level behavior change requires comprehensive multicomponent, multisector approaches. Our model also highlights a dichotomy between the results from the sprawling, car-dependent HIC city type and the LIC and MIC city types. The physical activity-SDG synergy is notable in the car-dependent HIC type modeled. In these types of settings, some physical activity strategies may be relatively feasible and often popular, but our results suggest that they may have a limited impact on population levels of physical activity and climate change mitigation if implemented without complementary approaches to reduce car use. Given the disproportionate contribution of the motorized transport sector in these settings to global carbon emissions, reducing car dependency is clearly important for addressing both local public health (physical inactivity-, traffic-, and air pollution-related deaths) and global planetary hazards (climate change). Meanwhile, in LMIC cities where directly attacking these same sustainability indicators runs into political challenges because it is perceived as stunting economic development and holding LMICs responsible for the sins of HICs, physical activity promotion strategies could offer a double win. Our model indicates that active transport and recreational physical activity could increase in LMIC cities with similar characteristics to the typologies modeled, with concomitant reductions in 
traffic deaths and air pollution, while also making progress toward climate change mitigation, even if implemented without complementary strategies to reduce car use. In spite of this evidence, few cities and countries around the world are currently implementing bold, atscale synergistic strategies to increase physical activity, enhance health, and ensure our planet's sustainability. Public health history and our findings suggest that to do this, we must embrace a broad multisectoral approach — one in which public health engages other sectors around their values and needs, using physical activity promotion as a lever for healthier people in a healthier planet.

\section{Acknowledgments}

The authors express their gratitude to several people who contributed to the work presented in this article. The authors thank Dr. Jason Thompson for reviewing and providing critical feedback to an early draft of this article. The authors also thank Liyan Jin, Shaui Xu, Eugen Resendiz, Aine O'Connor, and Joanna Sweeting for their assistance in different phases of the scoping review. The authors thank Joanne Song for her help in data gathering and cleaning to inform model calibration and Pierre James for his assistance collecting the data from the GooglePlaces API (Google LLC, Mountain View, CA), which was used to inform the model environment. The authors thank Abiodun Oluyomi and Adewale Oyeyemi for their valuable insights on low-income country city typologies and the Lancet Physical Activity Series 3 authors and executive committee members who participated in the conceptual linkage exercise. The authors also acknowledge that some of the data used in this article were obtained through Towards an Integrated Global Transport and Health Assessment Tool (TIGTHAT), an Medical Research Council (MRC) Global Challenges Project MR/P024408/1. D.S.'s work for this article was partially supported by Washington University in St. Louis, Center for Diabetes Translation Research (CDTR) (grant number P30DK092950 from the National
Institute of Diabetes and Digestive and Kidney Diseases [NIDDK]) and by the Cooperative Agreement Number U48DP006395 from the Centers for Disease Control and Prevention. I.S.'s work for this article was supported by the Salud Urbana en América Latina (SALURBAL)/Urban Health in Latin America Project, which is funded by the Wellcome Trust, UK (grant 205177/Z/16/Z). R.G.'s work for this article was partially supported by TIGTHAT, an MRC Global Challenges Project MR/ P024408/1. D.D.'s work for this article was supported by Heart Foundation Australia. None of the funding organizations listed played any role in the decisions related to the article. The content of this article is solely the responsibility of the authors and does not necessarily represent the official views of any of the funding agencies supporting this work. All authors declare no conflicts of interest. D.S. conceptualized the article and served as team lead for all aspects of the work; she developed methods for and analyzed the data on the conceptual linkage and scoping review sections; she drafted the introduction, conceptual linkage, scoping review, and discussion sections of the manuscript and integrated all of the coauthor contributions into a final draft. L.G. led the agent-based model section, including data gathering, development, analysis, and reporting (tables, figures, and section drafts); he actively contributed to all other sections of the manuscript. R.R. led the development of Table 2, and substantially contributed to the methodological protocols developed for the conceptual linkage exercise. I.S. was a key contributor to the agent-based model section of the article and worked closely with L.G. and R.G. on the development, testing, and reporting of the modeling exercise; she developed the figures pertaining to the agent-based model and extracted the spatial data used to inform the distribution of locations in the model through the GooglePlaces API. R.G. contributed to the development of the agent-based model and led air pollution and road traffic death modeling, working closely with L.G. and I.S. J.S. provided expert knowledge on case studies from around the world, drafted Table 5, and contributed to interpretation of findings. P.H. helped in developing the overall structure

\section{Table 6 Recommendations for Trans-Sectoral, Synergistic Action to Promote Physical Activity and Achieve the UN SDGs}

Common objectives for physical activity promotion and SDG achievement

- Reducing the burden of noncommunicable diseases

- Increasing the availability of and access to sustainable transport

- Increasing the availability of and access to green spaces

- Reducing air pollution and its health effects

- Reducing traffic injuries and deaths

- Reducing carbon emissions

- Reducing socioeconomic and gender-based inequalities

- Improving mental health

- Reducing violence and crime

General recommendations for achieving synergistic action across sectors

- Adopt a systems approach for addressing physical activity and SDGs globally: understand the dynamic and interconnected nature of the system to enact effective and sustainable solutions.

- Carefully consider the local context when designing and implementing multicomponent and multisectoral policies for tackling the physical inactivity pandemic and the sustainable development agenda across settings. Identifying local priorities can help increase public support and political will for action.

Recommendations for international agencies

United Nations

World Health Organization
- Integrate the principle of Health-in-All-Policies across all UN recommendations, action plans, and global monitoring systems.

- Use evidence to encourage physical activity promotion (best investments) as a strategy for attaining health- (SDG 3) and nonhealth-related SDGs (SDGs 5, 9, 10, 11, 13, and 16).

- Support all countries, and particularly LMICs, in successfully implementing all aspects of GAPPA. This should include clear guidance and facilitation for engaging multiple sectors (including nonhealth-related ones) for implementing physical activity-promoting policies.

- Track countries' progress toward GAPPA objectives as well as toward SDG cobenefits resulting from physical activity promotion. 


\section{Table 6 (continued)}

\section{Recommendations for government sectors}

Health

- Elevate the urgency of physical activity promotion by prioritizing it as an important stand-alone issue with health, environmental, social, economic, and planetary benefits.

- Highlight the full range of health benefits of physical activity promotion. This means not only highlighting cardiometabolic and cancer-related benefits but also expected population health improvements due to reductions in traffic-related injuries and deaths, reduced morbidity and mortality due to air pollution exposure, and improved mental health.

- Work closely with other key sectors (eg, transportation, planning, environment, etc) to implement effective solutions and maximize impact.

Transportation

- Emphasize the benefits of physical activity for both health and the planet in primary care settings.

- Adopt a Health-in-All-Policies approach to transportation engineering and planning. This should result in transportation systems that prioritize active travel through widespread and safe walking, cycling, and public transit infrastructure.

- In sprawling, car-dependent HIC cities, transport policies disincentivizing car use are needed and should be implemented in close coordination with other key sectors (eg, tax and revenue departments, planning, etc), and accompanied by complementary strategies to shift social norms that currently favor car travel.

- Prioritize the principle of equity in access to safe, affordable, clean, and healthy urban mobility options for all.

- Work closely with health, planning, and environmental sectors of government to ensure the adoption of a synergistic approach for promoting efficient mobility, physical activity and health, equity, safety, clean air, and planetary health.

- Work with the health sector to develop indicators to track the impact of implementing active and sustainable transport policies on health and urban mobility outcomes.

Planning

- Adopt a Health-in-All-Policies approach to city planning for promoting health and reducing sprawl and spatial health inequalities. This should result in cities that prioritize the principle of compact and mixed land use with strong emphasis on equitable access to high-quality public open spaces and recreational areas.

- Work closely with health, transportation, and environmental sectors of government to ensure the adoption of a synergistic approach for attaining active populations in healthy, equitable, and livable cities.

- Work with the health sector to develop indicators to track the impact of implementing active and sustainable urban design on health, urban equity, economic, and livability outcomes.

Environment

- Adopt a Health-in-All-Policies approach, emphasizing the benefits of physical activity promotion strategies for clean air, lower air pollution-related morbidity and mortality, and climate change mitigation.

- Adopt physical activity promotion as an important part of the solution for achieving reduced particulate matter and carbon emissions in cities.

- Work closely with health, transportation, and planning sectors of government to ensure the adoption of a synergistic approach for climate change mitigation and improved local air quality.

- In sprawling, car-dependent HIC cities, work closely with other sectors (transportation, tax and revenue, and planning) for implementing solutions to reduce particulate matter and carbon emissions resulting from private car use.

- In sprawling, car-dependent HIC cities, implement multisectoral strategies to reduce the social desirability of cars and driving while increasing the availability, coverage, safety, and attractiveness of active and sustainable mobility options.

- Work with the health, urban planning, and transportation sectors in evaluating the environmental and health impacts of physical activity promotion policies.

- Disseminate the environmental benefits of physical activity promotion to raise the urgency and political will for implementing synergistic actions.

- Adopt an equity-focused agenda, emphasizing everyone's right to live in clean, healthy, accessible, and sustainable environments.

\section{Recommendations for the academic sector}

Researchers

Universities/research institutions
- Prioritize translation and implementation science for identifying real-world solutions to scaling up physical activity promotion strategies for which there is sufficient evidence of positive impacts for health and SDGs (best investments 2, 3, and 6: active transportation systems, active urban design, and community wide approaches).

- Conduct research to confirm the plausible links between best investments 1 (whole of school approaches), 4 (physical activity promotion through primary care), 5 (mass media campaigns), and 7 (sports for all) and multiple SDGs. Team science and innovative research approaches (natural experiments, communityengaged research, practice-based evidence, and systems science) are encouraged.

- Conduct more research in LMICs to ensure that locally relevant, evidence-based solutions for promoting physical activity and achieving SDGs are available.

- Embrace broad dissemination plans that go beyond the use of traditional scientific outlets and reach key stakeholders across sectors.

- Provide strong and sustained structural support for transdisciplinary research.

- Value policy relevance, real-world impact, knowledge translation, and "team science" in academic hiring and promotion. 


\section{Table 6 (continued)}

- Design and implement sustainable funding schemes to support transdisciplinary research focused on realworld solutions to large-scale global challenges (ie, testing large-scale strategies to tackle the physical inactivity pandemic, attain the SDGs).

- Embrace and encourage the use of nontraditional research designs, including natural experiments and systems science (vs small controlled randomized trials with no scalability or real-world potential).

- Provide flexible funding opportunities to support opportunistic evaluations of environmental strategies and policy changes on multiple outcomes.

- Provide support to strengthen capacity for physical activity promotion and sustainability research in LMICs.

- Require broad dissemination plans that go beyond the use of traditional scientific outlets to ensure that new evidence reaches key stakeholders across sectors.

\section{Recommendations for civil society}

Nongovernmental organizations and society at large
- Advocate for heightened political commitment for synergistically addressing the dual issue of physical inactivity and sustainable development.

- Demand that elected officials implement bold policy actions prioritizing human, societal, and planetary health. This includes prioritizing active transportation systems (including reducing car dependency), active urban design strategies, and community-wide approaches.

Abbreviations: GAPPA, Global Action Plan on Physical Activity; HIC, high-income countries; LIMCs, low- and middle-income countries; SDGs, Sustainable Development Goals; UN, United Nations.

of the article (integration of all methods and results) and provided critical input or the development of Table 2, the discussion, limitations, and conclusions sections. D.D. was involved in the original conceptualization of this article; she led the development of Table 6 ; she was actively involved in the development of all aspects of the work throughout the manuscript development process. M.P. helped conceptualize this article (with D.S. and D.D.), was actively involved in the development of all aspects of the work, and drafted key sections of the manuscript, including the opening and closing paragraphs. All authors critically reviewed the full manuscript.

\section{References}

1. Sachs JD. From millennium development goals to sustainable development goals. Lancet. 2012;379(9832):2206-2211. PubMed ID: 22682467 doi:10.1016/S0140-6736(12)60685-0

2. United Nations. United Nations Sustainable Development Goals. 2015. https://sustainabledevelopment.un.org/. Accessed August 8, 2019.

3. World Health Organization. Stronger Collaboration, Better Health: Global Action Plan for Healthy Lives and Well-Being for All. Strengthening Collaboration Among Multilateral Organizations to Accelerate Country Progress on the Health-Related Sustainable Development Goals. USA: World Health Organization; 2019.

4. Kohl HW 3rd, Craig CL, Lambert EV, et al. The pandemic of physical inactivity: global action for public health. Lancet. 2012;380(9838): 294-305. PubMed ID: 22818941 doi:10.1016/S0140-6736(12) 60898-8

5. Lee IM, Shiroma EJ, Lobelo F, et al. Effect of physical inactivity on major non-communicable diseases worldwide: an analysis of burden of disease and life expectancy. Lancet. 2012;380(9838):219-229. PubMed ID: 22818936 doi:10.1016/S0140-6736(12)61031-9

6. Ding D, Lawson KD, Kolbe-Alexander TL, et al. The economic burden of physical inactivity: a global analysis of major non-communicable diseases. Lancet. 2016;388(10051):1311-1324. PubMed ID: 27475266 doi:10.1016/S0140-6736(16)30383-X

7. Sallis R, Young DR, Tartof SY, et al. Physical inactivity is associated with a higher risk for severe COVID-19 outcomes: a study in 48440 adult patients [published online April 13, 2021]. Br J Sports Med. doi:10.1136/bjsports-2021-104080
8. Chastin SFM, Abaraogu U, Bourgois JG, et al. Effects of regular physical activity on the immune system, vaccination and risk of community-acquired infectious disease in the general population: systematic review and meta-analysis [published online April 20, 2021]. Sports Med. 1-14. doi:10.1007/s40279-021-01466-1

9. Reis RS, Salvo D, Ogilvie D, et al. Scaling up physical activity interventions worldwide: stepping up to larger and smarter approaches to get people moving. Lancet. 2016;388(10051):13371348. PubMed ID: 27475273 doi:10.1016/S0140-6736(16)30728-0

10. Rudolph L, Caplan J, Ben-Moshe K, Dillon L. Health in All Policies: A Guide for State and Local Governments. Washington, DC and Oakland: American Public Health Association and Public Health Institute; 2013.

11. Ståhl T, Wismar M, Ollila E, Lahtinen E, Leppo K. Health in All Policies: Prospects and Potentials. Finland: Finnish Ministry of Social Affairs and Health; 2006.

12. Pratt M, Salvo D, Cavill N, et al. An international perspective on the nexus of physical activity research and policy. Environ Behav. 2016;48(1):37-54. doi:10.1177/0013916515609668

13. Hallal PC, Andersen LB, Bull FC, et al. Global physical activity levels: surveillance progress, pitfalls, and prospects. Lancet. 2012; 380(9838):247-257. PubMed ID: 22818937 doi:10.1016/S01406736(12)60646-1

14. Sallis JF, Bull F, Guthold R, et al. Progress in physical activity over the Olympic quadrennium. Lancet. 2016;388(10051):1325-1336. PubMed ID: 27475270 doi:10.1016/S0140-6736(16)30581-5

15. Heath GW, Parra DC, Sarmiento OL, et al. Evidence-based intervention in physical activity: lessons from around the world. Lancet. 2012;380(9838):272-281. PubMed ID: 22818939 doi:10.1016/ S0140-6736(12)60816-2

16. Pratt M, Perez LG, Goenka S, et al. Can population levels of physical activity be increased? Global evidence and experience. Prog Cardiovasc Dis. 2015;57(4):356-367. PubMed ID: 25304047 doi:10.1016/ j.pcad.2014.09.002

17. Centers for Disease Control and Prevention. The Community Guide. Guide to Community Preventive Services. Physical Activity Findings. Atlanta, GA: Centers for Disease Control and Prevention. 2020. https://www.thecommunityguide.org/topic/physical-activity. Accessed February 2, 2020.

18. Bull FC, Gauvin L, Bauman A, Shilton T, Kohl HW 3rd, Salmon A. The Toronto Charter for Physical Activity: a global call for action. $J$ 
Phys Act Health. 2010;7(4):421-422. PubMed ID: 20683082 doi:10. 1123/jpah.7.4.421

19. Das P, Horton R. Rethinking our approach to physical activity. Lancet. 2012;380(9838):189-190. PubMed ID: 22818931 doi:10. 1016/S0140-6736(12)61024-1

20. Das P, Horton R. Physical activity-time to take it seriously and regularly. Lancet. 2016;388(10051):1254-1255. PubMed ID: 27475269 doi:10.1016/S0140-6736(16)31070-4

21. Hallal PC, Bauman AE, Heath GW, Kohl HW 3rd, Lee IM, Pratt M. Physical activity: more of the same is not enough. Lancet. 2012; 380(9838):190-191. PubMed ID: 22818932 doi:10.1016/S01406736(12)61027-7

22. World Health Organization. Global Action Plan on Physical Activity 2018-2030: More Active People for a Healthier World. Geneva, Switzerland: World Health Organization; 2018.

23. Briss PA, Brownson RC, Fielding JE, Zaza S. Developing and using the guide to community preventive services: lessons learned about evidence-based public health. Annu Rev Public Health. 2004;25(1):281302. doi:10.1146/annurev.publhealth.25.050503.153933

24. Brown DR, Soares J, Epping JM, et al. Stand-alone mass media campaigns to increase physical activity a community guide updated review. Am J Prev Med. 2012;43(5):551-561. PubMed ID: 23079180 doi:10.1016/j.amepre.2012.07.035

25. Robinson MN, Tansil KA, Elder RW, et al. Mass media health communication campaigns combined with health-related product distribution a community guide systematic review. Am J Prev Med. 2014;47(3):360-371. PubMed ID: 25145620 doi:10.1016/j. amepre.2014.05.034

26. Buchanan LR, Rooks-Peck CR, Finnie RKC, et al. Reducing recreational sedentary screen time: a community guide systematic review (vol 50, pg 402, 2016). Am J Prev Med. 2016;50(6):809. doi:10.1016/ j.amepre.2016.03.006

27. Knopf JA, Finnie RKC, Peng Y, et al. School-based health centers to advance health equity a community guide systematic review. Am J Prev Med. 2016;51(1):114-126. PubMed ID: 27320215 doi:10.1016/ j.amepre.2016.01.009

28. Njie GJ, Proia KK, Thota AB, et al. Clinical decision support systems and prevention a community guide cardiovascular disease systematic review. Am J Prev Med. 2015;49(5):784-795. PubMed ID: 26477805 doi:10.1016/j.amepre.2015.04.006

29. Piercy KL, Troiano RP, Ballard RM, et al. The physical activity guidelines for Americans. JAMA. 2018;320(19):2020-2028. PubMed ID: 30418471 doi:10.1001/jama.2018.14854

30. Powell KE, King AC, Buchner DM, et al. The scientific foundation for the physical activity guidelines for Americans, 2nd edition. J Phys Act Health. 2019;16(1):1-11. doi:10.1123/jpah.2018-0618

31. UK Ministry of Health. UK Chief Medical Officers' Physical Activity Guidelines. UK Goverment: Department of Health and Social Care, Llwodraeth Cymru Welsh Government, Department of Health Northern Ireland and the Scottish Government. 2019.

32. Willumsen J, Bull F. Development of WHO guidelines on physical activity, sedentary behavior, and sleep for children less than 5 years of age. J Phys Act Health. 2020;17(1):96-100. PubMed ID: 31877559 doi:10.1123/jpah.2019-0457

33. Bull FC, Al-Ansari SS, Biddle S, et al. World Health Organization 2020 guidelines on physical activity and sedentary behaviour. $\mathrm{Br} J$ Sports Med. 2020;54(24):1451-1462. PubMed ID: 33239350 doi:10. 1136/bjsports-2020-102955

34. Varela AR, Salvo D, Pratt M, et al. Worldwide use of the first set of physical activity Country Cards: The Global Observatory for Physical Activity-GoPA! Int J Behav Nutr Phys. 2018;15(1):29. doi:10. 1186/s12966-018-0663-7
35. Lachat C, Otchere S, Roberfroid D, et al. Diet and physical activity for the prevention of noncommunicable diseases in low- and middleincome countries: a systematic policy review. PLoS Med. 2013;10(6): e1001465. PubMed ID: 23776415 doi:10.1371/journal.pmed.1001465

36. Min J, Zhao Y, Slivka L, Wang Y. Double burden of diseases worldwide: coexistence of undernutrition and overnutrition-related non-communicable chronic diseases. Obes Rev. 2018;19(1):49-61. PubMed ID: 28940822 doi:10.1111/obr.12605

37. Maher D, Ford N, Unwin N. Priorities for developing countries in the global response to non-communicable diseases. Global Health. 2012;8(1):14. PubMed ID: 22686126 doi:10.1186/1744-8603-8-14

38. Salvo D, Sarmiento OL, Reis RS, et al. Where Latin Americans are physically active, and why does it matter? Findings from the IPENadult study in Bogota, Colombia; Cuernavaca, Mexico; and Curitiba, Brazil. Prev Med. 2017;103(suppl):S27-S33. PubMed ID: 27609744 doi:10.1016/j.ypmed.2016.09.007

39. Strain T, Wijndaele K, Garcia L, et al. Levels of domain-specific physical activity at work, in the household, for travel and for leisure among 327789 adults from 104 countries. Br J Sports Med. 2020; 54(24):1488-1497. PubMed ID: 33239355 doi:10.1136/bjsports2020-102601

40. Jauregui A, Salvo D, Medina C, Barquera S, Hammond D. Understanding the contribution of public- and restricted-access places to overall and domain-specific physical activity among Mexican adults: a cross-sectional study. PLoS One. 2020;15(2):e0228491. PubMed ID: 32032390

41. Rutter H, Savona N, Glonti K, et al. The need for a complex systems model of evidence for public health. Lancet. 2017;390(10112):26022604. PubMed ID: 28622953 doi:10.1016/S0140-6736(17)31267-9

42. Snow J. On the mode of communication of cholera. Edinb Med J. 1856;1(7):668-670. PubMed ID: 29647347

43. Iheozor-Ejiofor Z, Worthington HV, Walsh T, et al. Water fluoridation for the prevention of dental caries. Cochrane Database Syst Rev. 2015;(6):CD010856.

44. Andersson M, de Benoist B, Rogers L. Epidemiology of iodine deficiency: salt iodisation and iodine status. Best Pract Res Clin Endocrinol Metab. 2010;24(1):1-11. PubMed ID: 20172466 doi:10. 1016/j.beem.2009.08.005

45. Obican SG, Finnell RH, Mills JL, Shaw GM, Scialli AR. Folic acid in early pregnancy: a public health success story. Faseb J. 2010; 24(11):4167-4174. PubMed ID: 20631328

46. Tricco AC, Lillie E, Zarin W, et al. PRISMA Extension for Scoping Reviews (PRISMA-ScR): checklist and explanation. Ann Intern Med. 2018;169(7):467-473. PubMed ID: 30178033 doi:10.7326/M18-0850

47. Wohlin C. Guidelines for snowballing in systematic literature studies and a replication in software engineering. Paper presented at: Proceedings of the 18th International Conference on Evaluation and Assessment in Software Engineering, London, UK; 2014.

48. Althoff T, Sosic R, Hicks JL, King AC, Delp SL, Leskovec J. Largescale physical activity data reveal worldwide activity inequality. Nature. 2017;547(7663):336-339. PubMed ID: 28693034 doi:10. 1038/nature23018

49. Lambert EV, Kolbe-Alexander T, Adlakha D, et al. Making the case for "physical activity security": the 2020 WHO guidelines on physical activity and sedentary behaviour from a Global South perspective. $\mathrm{Br}$ J Sports Med. 2020;54(24):1447-1448. PubMed ID: 33239348 doi:10.1136/bjsports-2020-103524

50. Straker L, Holtermann A, Lee I-M, van der Beek AJ, Stamatakis E. Privileging the privileged: the public health focus on leisure time physical activity has contributed to widening socioeconomic inequalities in health. Brt J Sports Med. 2020;55:525-526. doi:10.1136/ bjsports-2020-103356 
51. Mielke GI, da Silva ICM, Kolbe-Alexander TL, Brown WJ. Shifting the physical inactivity curve worldwide by closing the gender gap. Sports Medicine. 2018;48(2):481-489. PubMed ID: 28647914 doi:10.1007/s40279-017-0754-7

52. Simoes EJ, Hallal PC, Siqueira FV, et al. Effectiveness of a scaled up physical activity intervention in Brazil: a natural experiment. Prev Med. 2017;103S:S66-S72. PubMed ID: 27687538

53. Reis RS, Yan Y, Parra DC, Brownson RC. Assessing participation in community-based physical activity programs in Brazil. Med Sci Sports Exerc. 2014;46(1):92-98. PubMed ID: 23846162 doi:10. 1249/MSS.0b013e3182a365ae

54. Gomez LF, Sarmiento R, Ordonez MF, et al. Urban environment interventions linked to the promotion of physical activity: a mixed methods study applied to the urban context of Latin America. Soc Sci Med. 2015;131:18-30. PubMed ID: 25748111 doi:10.1016/j. socscimed.2015.02.042

55. Lorenc T, Oliver K. Adverse effects of public health interventions: a conceptual framework. J Epidemiol Community Health. 2014;68(3): 288-290. PubMed ID: 24336237 doi:10.1136/jech-2013-203118

56. Victora CG, Joseph G, Silva ICM, et al. The inverse equity hypothesis: analyses of institutional deliveries in 286 national surveys. Am J Public Health. 2018;108(4):464-471. PubMed ID: 29470118 doi:10. 2105/AJPH.2017.304277

57. The Lancet. 50 years of the inverse care law. Lancet. 2021; 397(10276):767. doi:10.1016/S0140-6736(21)00505-5

58. Engle PL, Fernald LC, Alderman H, et al. Strategies for reducing inequalities and improving developmental outcomes for young children in lowincome and middle-income countries. Lancet. 2011;378(9799): 1339-1353. PubMed ID: 21944378 doi:10.1016/S0140-6736(11)60889-1

59. Muralidharan K, Prakash N. Cycling to school: increasing secondary school enrollment for girls in India. Am Econ J Appl Econ. 2017;9(3):321-350. doi:10.1257/app.20160004

60. Brown WJ, Mielke GI, Kolbe-Alexander TL. Gender equality in sport for improved public health. Lancet. 2016;388(10051):1257-1258. PubMed ID: 27475268 doi:10.1016/S0140-6736(16)30881-9

61. Badham J, Chattoe-Brown E, Gilbert N, Chalabi Z, Kee F, Hunter RF. Developing agent-based models of complex health behaviour. Health Place. 2018;54:170-177. PubMed ID: 30290315 doi:10.1016/j. healthplace.2018.08.022

62. Ben-Akiva M, Lerman SR. Discrete Choice Analysis: Theory and Application to Travel Demand. Cambridge, MA: Transportation Studies, MIT Press; 2018.

63. Acemoglu D, Ozdaglar A. Opinion dynamics and learning in social networks. Dyn Games Appl. 2011;1(1):3-49. doi:10.1007/s13235010-0004-1

64. Martins AC. Continuous opinions and discrete actions in opinion dynamics problems. Int J Mod Phys C. 2008;19(04):617-624. doi:10. 1142/S0129183108012339

65. Zimmerman FJ. Habit, custom, and power: a multi-level theory of population health. Soc Sci Med. 2013;80:47-56. PubMed ID: 23415591 doi:10.1016/j.socscimed.2012.12.029

66. Garcia LMT, Roux AVD, Martins ACR, Yang Y, Florindo AA. Exploring the emergence and evolution of population patterns of leisure-time physical activity through agent-based modelling. Int $J$ Behav Nutr Phy. 2018;15.

67. Garcia LMT, Roux AVD, Martins ACR, Yang Y, Florindo AA. Development of a dynamic framework to explain population patterns of leisure-time physical activity through agent-based modeling. Int $J$ Behav Nutr Phy. 2017;14(1):111. doi:10.1186/s12966-017-0553-4

68. Garcia LMT, Diez Roux AV, Martins ACR, Yang Y, Florindo AA. Exploring the emergence and evolution of population patterns of leisure-time physical activity through agent-based modelling. Int $J$
Behav Nutr Phys Act. 2018;15(1):112. PubMed ID: 30453997 doi:10. 1186/s12966-018-0750-9

69. Jackson C, Presanis A, Conti S, De Angelis D. Value of information: sensitivity analysis and research design in Bayesian evidence synthesis. J Am Stat Assoc. 2019;114(528):1436-1449. PubMed ID: 32165869 doi:10.1080/01621459.2018.1562932

70. Johnson R, Woodcock J, de Nazelle A, et al. A guide to value of information methods for prioritising research in health impact modelling. arXiv preprint arXiv:190500008. 2019.

71. Strain T, Brage S, Sharp SJ, et al. Use of the prevented fraction for the population to determine deaths averted by existing prevalence of physical activity: a descriptive study. Lancet Glob Health. 2020;8(7):e920-e930. PubMed ID: 32562648 doi:10.1016/S2214-109X(20)30211-4

72. Buehler R. Determinants of transport mode choice: a comparison of Germany and the USA. J Transp Geogr. 2011;19(4):644-657. doi:10.1016/j.jtrangeo.2010.07.005

73. Freemark J. Travel mode shares in the U.S. The Transport Politic: Databook; 2019. https://www.thetransportpolitic.com/databook/travelmode-shares-in-the-u-s/. Accessed May 1, 2021.

74. U.S. Environmental Protection Agency. Fast Facts. US Transportation Sector Greenhouse Gas Emissions: 1990-2018. Office of Transportation and Air Quality EPA-420-F-20-037; 2020. https://nepis. epa.gov/Exe/ZyPDF.cgi?Dockey=P100ZK4P.pdf. Updated June 2020. Accessed May 4, 2021.

75. Giuliano G, Dargay J. Car ownership, travel and land use: a comparison of the US and Great Britain. Transport Res A Pol Pract. 2006;40(2):106-124. doi:10.1016/j.tra.2005.03.002

76. The Community Preventive Services Task Force. Physical activity: built environment approaches combining transportation system interventions with land use and environmental design. 2016. https://www.the communityguide.org/findings/physical-activity-built-environment-app roaches. Accessed October 28, 2020.

77 World Health Organization. Urgent health challenges for the next decade. 2020. https://www.who.int/news-room/photo-story/photostory-detail/urgent-health-challenges-for-the-next-decade. Accessed January 13, 2020.

78. Sumner A. Global poverty and the new bottom billion: what if threequarters of the world's poor live in middle-income countries? IDS Working Papers. 2010;2010(349):01-43. doi:10.1111/j.2040-0209. 2010.00349_2.x

79. Gu J, Mohit B, Muennig PA. The cost-effectiveness of bike lanes in New York City. Injury Prev. 2017;23(4):239-243. doi:10.1136/ injuryprev-2016-042057

80. Marques R, Hernandez-Herrador V, Calvo-Salazar M, Garcia-Cebrian JA. How infrastructure can promote cycling in cities: lessons from Seville. Res Transp Econ. 2015;53:31-44.

81. Montes F, Sarmiento OL, Zarama R, et al. Do health benefits outweigh the costs of mass recreational programs? An economic analysis of four Ciclovia programs. J Urban Health. 2012;89(1):153170. PubMed ID: 22170324 doi:10.1007/s11524-011-9628-8

82. Cohen DA, Marsh T, Williamson S, Golinelli D, McKenzie TL. Impact and cost-effectiveness of family fitness zones: a natural experiment in urban public parks. Health Place. 2012;18(1):3945. PubMed ID: 22243905 doi:10.1016/j.healthplace.2011.09.008

83. Sarmiento O, Pedraza C, Triana C, Díaz D, González S, Montero S. Promotion of recreational walking: Case study of the CiclovíaRecreativa of Bogotá. In: Mulley C, Gebel K, Ding D, eds. Walking: Connecting Sustainable Transport with Health. Bingley, UK: Emerald Publishing Limited; 2017:275-286.

84. City of Copenhagen. The CPH 2025 climate plan. 2015. https:// urbandevelopmentcph.kk.dk/artikel/cph-2025-climate-plan. Accessed October 28, 2020. 
85. City of Copenhagen. Enjoy life, Copenhageners. Copenhaghen, Denmark: Health and Care Administration of the City. 2015. https://www. kk.dk/sites/default/files/HEALTH\%20POLICY\%202015-2025.pdf

86. EcoMobility. EcoMobility Alliance. 2019. https://ecomobility.org/ ecomobility-alliance/. Accessed May 1, 2021.

87. EcoMobility. Transport \& Health. 2019. https://ecomobility.org/ourwork/transport-and-health/. Accessed May 1, 2021.

88. Union of Concerned Scientists. Each Country's Share of CO2 Emissions. 2019. https://www.ucsusa.org/resources/each-countrys-shareco2-emissions. Updated October 10, 2019. Accessed October 28, 2020.
89. Mattioli G, Anable J, Vrotsou K. Car dependent practices: findings from a sequence pattern mining study of UK time use data. Transport Res A Pol Pract. 2016;89:56-72. doi:10.1016/j.tra.2016. 04.010

90. Barquera S, Campos I, Rivera JA. Mexico attempts to tackle obesity: the process, results, push backs and future challenges. Obes Rev. 2013;14:69-78. PubMed ID: 24103026 doi:10.1111/obr.12096

91. Warner KE, Mendez D. Tobacco control policy in developed countries: yesterday, today, and tomorrow. Nicotine Tob Res. 2010;12(9):876-887. PubMed ID: 20702814 doi:10.1093/ntr/ntq125 